\title{
Optic Perineuritis Secondary to Sjogreen's Syndrome: Case Report
}

\section{Juliana Emy Tolachinski Oikawa ${ }^{1^{*}}$, Julia Gomes Leite de Souza ${ }^{1}$, Vitória Caroline Cardoso Ferreira ${ }^{1}$, Paulo Roberto Wille, MD, PhD², Laura Fiuza Parolin, $M D^{3}$ and Marcus Vinícius Magno Gonçalves, $M D, P h D^{3}$}

\author{
${ }^{1}$ Medical Students, Universidade da Região de Joinville, Brazil \\ ${ }^{2}$ Department of Radiology, Universidade da Região de Joinville, Brazil \\ ${ }^{3}$ Department of Neurology, Universidade da Região de Joinville, Brazil
}

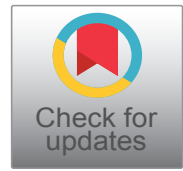

*Corresponding author: Juliana Emy Tolachinski Oikawa, Medical Students, Universidade da Região de Joinville, Joinville, SC 89219-710, Brazil

\section{Keywords \\ Optic perineurits, Sjogreen, Neuroimmunology}

Optic perineuritis (OPN) is a rare inflammatory disease involving the optic nerve sheath [1], causing pain and disc edema and is often bilateral [2]. The diagnosis of OPN is commonly based on magnetic resonance imaging (MRI) findings and clinical features [3]. In MRI it is possible to visualize a circumferential enhancement around the intraorbital optic nerve with preservation of the nerve itself (doughnut sign) [4]. This is better seen in contrast-enhanced and suppressed coronal MRI sequences with fat. Magnetic resonance imaging may also show enhancement of orbital fat and slight increase in extraocular muscles [1]. The etiologies of OPN include syphilis $[5,6]$, tuberculosis $[7,8]$, herpes zoster [9], sarcoidosis $[10,11]$, Wegener's granulomatosis [12], granulomatosis associated with polyangiitis [13], giant cell arteritis [14,15] Crohn's disease [16], Behçet's disease [1], acute retinal necrosis [17]. However, in most cases, no specific etiology is identified and these cases are categorized as idiopathic OPN [18].

A 68-year-old woman started with a subacute onset of progressive visual acuity worsening associated with bilateral retrobulbar pain about 4 months ago. Fundoscopy was normal and reduced direct and consensual photo motor reflex. Sicca syndrome was confirmed in Schirmer test. Rheumatoid factor was positive (23.6) and anti-RO/LA antibody positive. Cranial MRI showed very thin and intense contrast enhancement along both optic nerve sheath and parotid edema associated (Figure 1) meeting the criteria of Sjogren syndrome (SS) [19]. We found no evidence of secondary SS suggesting a form primary.

Patient had clinical improvement of visual acuity and retroocular pain partially after pulse therapy with methylprednisolone. Rituximab maintenance patient every 6 months. SS is a rare cause and should not be forgotten as a differential diagnosis of optic perineurit.

\section{References}

1. Lai C, Sun Y, Wang J, Purvin VA, He Y, et al. (2015) Optic perineuritis in behçet disease. J Neuroophthalmol 35: 342347.

2. Lana-Peixoto MA (2002) Sistema sensorial-parte I-Revisão 1997-1999. Neurooftalmologia. Arquivos Brasileiros de Oftalmologia.

3. Tatsugawa M, Noma H, Mimura T, Funatsu H (2010) Highdose steroid therapy for idiopathic optic perineuritis: A case series. J Med Case Rep 4: 404.

4. Purvin V, Kawasaki A (2009) Optic perineuritis secondary to wegener's granulomatosis. Clin Exp Ophthalmol 37: 712-717.

5. Toshniwal $P$ (1987) Optic perineuritis with secondary syphilis. J ClinNeuroophthalmol 7: 6-10.

6. Lim SH, Heng LK, Puvanendran K (1990) Secondary syphilis presenting with optic perineuritis and uveitis. Ann Acad Med Singapore 19: 413-415. 

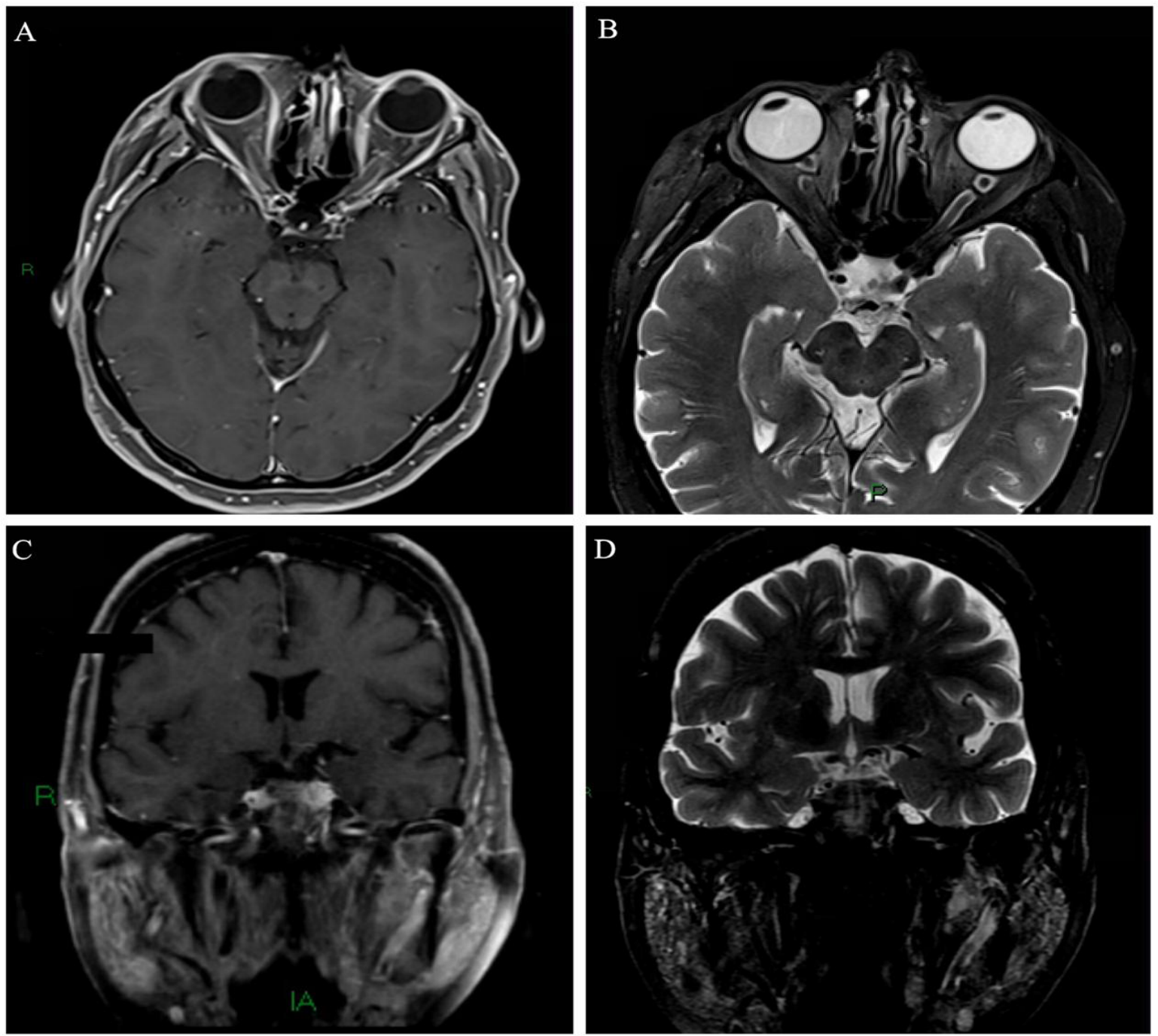

Figure 1: Axial A) T1-spin echo, after gadolinium iv injection and axial; B) T2 with fat saturation show a very thin and intense symmetrically contrast enhancement along both optic nerve sheath as well a high intensity thickening along of both optic perineural CSF space. Coronal C) T1-spin echo, after gadolinium i.v. injection and coronal; D) T2 with fat saturation reveal a symmetrical increase of parotidite glands.

7. Raghibi A, Wan Hitam WH, Noor RAM, Embong Z (2012) Optic perineuritis secondary to tuberculosis: A rare case presentation. Asian Pac J Trop Biomed 2: S1206-S1208.

8. Yates WB, Nothling S, Lawlor M (2019) Optic perineuritis due to tuberculosis. J Neuro-Ophthalmology 39: 257-259.

9. Bansal R, Singh R, Takkar A, Lal V (2017) Combined central retinal artery and vein occlusion with optic perineuritis following herpes zoster dermatitis in an immunocompetent child. Indian J Ophthalmol 65: 1233-1235.

10. Yu-Wai-Man P, Crompton DE, Graham JY, Black FM, Dayan MR (2017) Optic perineuritis as a rare initial presentation of sarcoidosis. Clin Exp Ophthalmol 35: 682-684.

11. Kidd DP, Burton BJ, Graham EM, Plant GT (2016) Optic neuropathy associated with systemic sarcoidosis. Neurol Neuroimmunol Neuroinflammation 3: e270.

12. Takazawa $T$, Ikeda $K$, Nagaoka $T$, Hirayama $T$, Yamamoto T, et al. (2014) Wegener granulomatosis-associated optic perineuritis. Orbit 33: 13-16.

13. Yoshitaka K, Kurumi A, Hirotoshi K, Hajime K (2017) Refractory optic perineuritis due to granulomatosis with polyangiitis successfully treated with methotrexate and myco- phenolate mofetil combination therapy. Eur J Rheumatol 4: 70-72.

14. Morotti A, Liberini $P$, Padovani A (2013) Bilateral optic perineuritis as the presenting feature of giant cell arteritis. BMJ Case Rep.

15. Pappolla A, Silveira F, Norscini J, Miquelini L, Patrucco L (2019) Bilateral optic perineuritis as initial presentation of giant cell arteritis. Neurologist 24: 26-28.

16. Mcclelland C, Zaveri M, Walsh R, Fleisher J, Galetta S (2012) Optic perineuritis as the presenting feature of crohn disease. J Neuroophthalmology 32: 345-347.

17. Byon IS, Jung JH, Kim HY, Park SW, Lee JE (2013) Optic perineuritis secondary to acute retinal necrosis. J Neuro-Ophthalmology 33: 419-421.

18. Hickman SJ (2016) Optic perineuritis. Curr Neurol Neurosci Rep 16: 16.

19. Vitali C, Bombardieri S, Jonsson R, Moutsopoulos HM, Alexander EL, et al. (2002) Classification criteria for sjögren's syndrome: A revised version of the European criteria proposed by the American-European consensus group. Ann Rheum Dis 61: 554-558. 